\title{
Numerical Simulations for Plasmonic Nano-antenna a-Si:H Solar Cell
}

A. García-Barrientos ${ }^{1}$, J. Plaza-Castillo², J.A. Hoyo-Montaño ${ }^{3}$, M.A. García-Ramírez ${ }^{4}$, R.E. BalderasNavarro $^{5}$, F.R. Castillo-Soria ${ }^{1}$ and U. Pineda-Rico ${ }^{1}$

1. Faculty of Science, Autonomous University of San Luis Potosi, SLP, México.

2. Department of Physics, Universidad del Atlántico, Barranquilla, Colombia.

3. Department of Electronics, Instituto Tecnológico de Hermosillo, Sonora, México.

4. Department of Electronics, Universidad de Guadalajara, Jalisco, México.

5. IICO, Autonomous University of San Luis Potosi, SLP, México.

The hydrogenated amorphous silicon (a-Si:H) appears as a promising material in the photovoltaic industry due to its high absorption coefficient and low manufacturing cost [1-2]. However, light management and control are forms crucial components in high efficiency solar cells. For example, the textured surfaces at the contacts of the solar cells can increase light trapping, such it is a yield important improvement of the over-all efficiency. A new concept of trapping light is the use of "plasmonics", the electronic response of free electrons to light interacting with metal nanostructures [3]. One of the most important experimental investigations of plasmonic enhancement for photovoltaic involved the scattering of silver nanoparticles in an organic solar cell [4].

In this work, numerical simulations of radiation for three optical nano-antennas in the form of a silver nano-needle were embedded in an a-Si:H solar cell were carried out. The structure showed in figure 1a was took account for these simulations, in this case a semi-sphere on top of the nano-needle is formed, which acts like a plano-convex lens, focusing light directly on the silver nano-needle antenna [5]. The a$\mathrm{Si}: \mathrm{H}$ thin film used for these simulations is showed in the figure $1 \mathrm{~b}$ [6]. We use finite-difference timedomain (FDTD) calculations to simulate the radiation for three silver nano-needle embedded in an a$\mathrm{Si}: \mathrm{H}$ thin film. The results are showed in the figure 1c for the three silver nano-needles in different positions, in this case we can see that the pattern radiation is omnidirectional as in a monopole antenna, so the photocurrents can be used to measure the effect of the nanolens combined with plasmonic nanoantenna inside the solar cell. The results show that we can obtain information about the gains in these nanostructures, which these will lead to increase the efficiency in the solar cell [7].

\section{References:}

[1] J Ma, et al., Solar Energy Materials and Solar Cells 123 (2014), p. 228.

[2] K Ding, et al., Solar Energy Materials and Solar Cells 95 (2011), p. 3318.

[3] G Conibeer, et al., Mater. Today 10(11) (2007), p. 42.

[4] M Westphalen, et al., Sol. Energy Mater. Sol. Cells 61(1) (2000), p. 97.

[5] M Di Vece et al., Opt Express 20 (2012), p. 27327.

[6] J Plaza-Castillo et al., Microscopy and Microanalysis 21(S3) (2015), p. 297.

[7] The authors acknowledge funding from the CONACYT-Mexico, research projects grant numbers 169062 and 204419. 


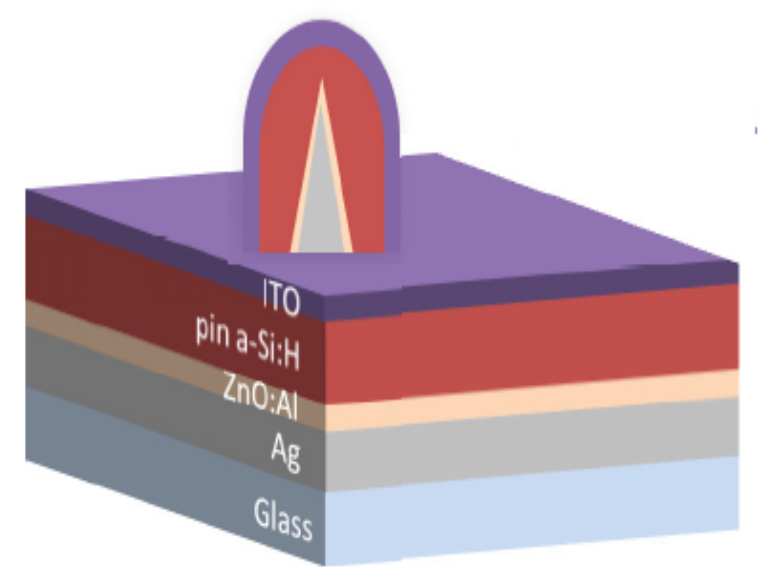

(a)

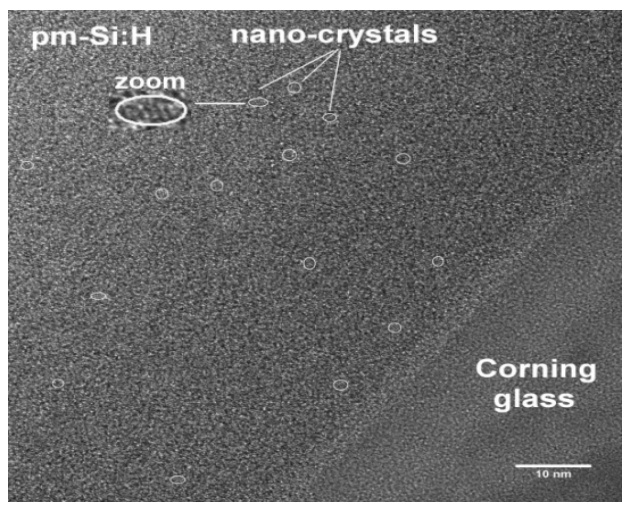

(b)
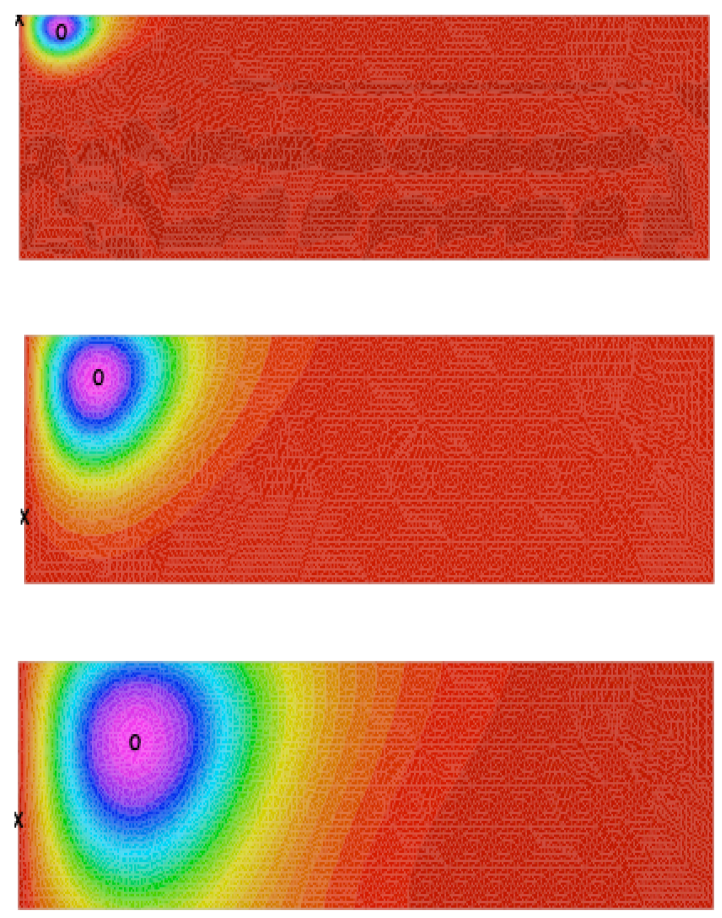

(c)

Figure 1. (a) Schematic depiction of the nanoneedle solar cell. The layer sequence is indicated [5]. (b) High resolution SEM micrographs of the a-Si:H thin film at 2000 mTorr, where nano-crystals appear. (c) Radiation for three optical nano-antennas in the form of a silver nanoneedles are embedded in an aSi:H solar cell. 